\title{
Eu me vejo: representação e representatividade nas obras literárias presentes no Programa Nacional Biblioteca da Escola 2013
}

\begin{abstract}
Resumo:
Este artigo apresenta os resultados da pesquisa de iniciação científica intitulada "Eu me vejo: representação e representatividade nas obras literárias presentes no Programa Nacional Biblioteca na Escola 2013" que teve como objetivo principal ler e investigar quais obras, do acervo do PNBE do ano de 2013, possuem protagonistas negros e, dentro dessas, como eram as representações étnicas. Para construir esta pesquisa, iniciei leituras e reflexões referentes aos estudos sobre raça no Brasil conforme Antonio Sergio Guimarães e sobre os conceitos de representação e representatividade - tendo como principal referência Stuart Hall. No segundo momento, desenvolvi uma análise das obras literárias selecionadas pelo PNBE, para verificar quais representações de etnia estão presentes nesse acervo. Dos 120 livros do acervo indicado para os últimos anos do ensino fundamental, averiguei que apenas quatro obras literárias possuem protagonistas negros.
\end{abstract}

\section{Palavras-chave:}

Literatura infanto-juvenil. PNBE. Representação. Raça. Representatividade.

\begin{abstract}
:
This paper presents the results of the undergraduate research project entitled: "Eu me vejo: representação e representatividade nas obras literárias presentes no Programa Nacional Biblioteca na Escola 2013", whose main objective was to read and investigate which works from PNBE's collection, from 2013, portray black main characters and how ethnical representations are built in these books. I started this research study with literature on two concepts: race, according to the studies of Antonio Sergio Guimarães; and representation and representativeness, with the main reference being Stuart Hall. In the second part of this study, I developed an analysis of literary works selected by PNBE to verify which ethnical representations are present in this collection. Out of the 120 books from the collection appointed to the last years of middle school, I verified that only four literary works have black main characters.
\end{abstract}

\section{Keywords:}

Children's and youth literature. PNBE. Representation. Race. Representativeness.

\footnotetext{
* Graduanda em Letras na Universidade Federal do Rio Grande do Sul. E-mail: thaisboardman@hotmail.com. ORCID iD: https://orcid.org/0000-0003-0020-1569.
} 


\section{Introdução}

A literatura é, como afirma Antonio Candido (2004), no texto "O direito à literatura", uma língua universal, pois sempre comunica algo a qualquer pessoa, e deve ser, portanto, um direito. E se temos o direito à literatura, deveríamos todos termos a oportunidade de nos vermos representados nas obras literárias. Ver-se representado é importante para todos os leitores, independentemente da idade, especialmente na infância e na juventude - por isso, a relevância das obras nas bibliotecas escolares, pois por meio delas a maioria dos jovens têm acesso aos livros.

Representatividade, no seu sentido cru e literal, significa tudo aquilo que para o leitor é representativo, que causa autoidentificação e afinidade de imediato. Em outras palavras, é quando o leitor consegue se ver na obra e/ou nas características da personagem (físicas ou psicológicas). É fundamental para todos os jovens, independente de seus traços fenotípicos, verem um exemplo de sucesso parecido com ele.

A demanda por representatividade vem conquistando cada vez mais espaço na política, no mercado de trabalho ou na esfera educacional. Ressignificar e produzir representações positivas sobre os negros, suas histórias, suas culturas e suas estéticas, é um dos papéis da educação e da literatura na escola que, desde janeiro de 2003, é regida por leis: tivemos a Lei $n^{\circ} 10.639$ que foi atualizada pela Lei $n^{\circ} 11.645$, em março de 2008, alterando a LDB (Lei de Diretrizes e Bases da Educação Nacional) ao introduzir o artigo 26. Estabelecendo em todo o território nacional,

[...] o estudo da história da África e dos africanos, a luta dos negros e dos povos indígenas no Brasil, a cultura negra e indígena brasileira e o negro e o índio na formação da sociedade nacional, resgatando as suas contribuições nas áreas social, econômica e política, pertinentes à história do Brasil.

$\$ 2^{\circ}$ Os conteúdos referentes à história e cultura afro-brasileira e dos povos indígenas brasileiros serão ministrados no âmbito de todo o currículo escolar, em especial nas áreas de educação artística e de literatura e história brasileiras. (BRASIL, 2008).

Sabendo que a infância é o momento mais importante para a construção de identidade e para apresentar noções de diversidade, a literatura infanto-juvenil, como material de grande circulação e enfocado em uma faixa etária específica, pode vir a ser um agente positivo na construção da identidade das crianças - principalmente para as crianças negras que muitas vezes não se veem nas obras -, pois é através da literatura que as crianças podem ter contato com diversas representatividades.

Um exemplo disso é o livro Heroínas negras brasileira em 15 cordéis (ARAES, 2017), nessa obra, a autora reconta uma parte da história do Brasil que foi apagada: as mulheres negras, suas práticas e atuações que influenciaram a formação do Brasil. São 15 histórias bem diversas entre si para promover que as mulheres negras têm percursos tão diferentes quanto os homens e podem representar e preencher variadas narrativas, aumentando a compreensão de crianças e adolescentes sobre a representatividade negra.

Para que a literatura infantil com personagens negros possa ser disseminada no ambiente escolar, é preciso que esteja disponível na escola. Esse caminho de disponibilizar livros para as escolas - em âmbito institucional - se dá desde 1998 com o PNBE (Programa Nacional Biblioteca da Escola), um grande promotor na distribuição de obras literárias no Brasil.

Tendo em vista esse contexto reflexivo, o artigo aqui apresentado organiza e resume a pesquisa que desenvolvo na Iniciação Científica, intitulada "Eu me vejo: representação e representatividade nas obras literárias presentes no Programa Nacional da Biblioteca na Escola 2013"1. Partindo de reflexões acerca de questões raciais (especificamente sua presença - ou ausência - na literatura juvenil contemporânea), a grande questão que moveu esta pesquisa foi pensar nas representações étnicas nos livros de literatura selecionados pelo PNBE do ano de 2013.

1. Pesquisa de Iniciação Científica desenvolvida em 2018/2 e 2019/1, vinculada à pesquisa "O livro é um convite: projetos de leitura e formação de leitores na Educação Básica”, sob orientação da Dr. a Caroline Valada Becker professora do Colégio de Aplicação da UFRGS. 


\section{As políticas públicas de incentivo à leitura}

As políticas públicas são ações, programas e decisões tomadas pelos governos com a participação (direta ou indireta) de entidades públicas ou privadas que se destinam a garantir certos direitos de cidadania para vários grupos da sociedade. Isto é, as políticas públicas são um processo que tem por objetivo resolver um problema público, tendo como exemplo a leitura no Brasil. A leitura é fundamental para a constituição do sujeito, pois contribui para a formação da identidade individual, com novas ideias, realidades e indivíduos diferentes. Reconhecemos que a escola é o espaço mais importante de formação de leitores, porém, ainda é escassa a qualidade da Educação Básica no Brasil, então se julga necessário a criação e a implementação de políticas públicas voltadas para o incentivo à leitura.

Segundo Eliana Yunes (1994, p. 12), no livro A formação do leitor: o papel das instituições de formação do professor para a educação fundamental, a política é

[...] uma ação do Estado como mobilizadora e articuladora das experiências e esforços da sociedade civil, das instituições não-governamentais e do próprio governo, que delineiem prioridades, associem recursos e invistam num programa coordenado que multiplique seus efeitos, descentralize as iniciativas e incorpore os resultados numa rede que facilite a extensão dos benefícios a outros grupos interessados.

Para a autora, a política pública é uma ação que deve ser sugerida em diferentes locais, pois não há vida em sociedade sem política. As políticas públicas buscam articular e apresentar soluções para melhorar questões pedagógicos, a partir de uma maior articulação entre a educação e a cultura. Através de políticas públicas, o governo brasileiro tem buscado promover ações que articulam, na Educação Básica, o acesso ao livro e à formação de leitores, como uma forma de melhorar a qualidade leitora dos brasileiros e de democratizar a leitura.

Segundo o livro Programa Nacional Biblioteca da Escola (PNBE): leitura e biblioteca nas escolas públicas brasileiras, "as primeiras ações voltadas para a biblioteca escolar e para o incentivo à leitura e à formação de leitores, como o Programa Salas de Leitura, tiveram início nos anos oitenta” (BRASIL, 2008, p. 7). Devido a uma grande procura, em 1988, o programa foi alterado para Salas de Leitura/Bibliotecas Escolares. Assim, foram criadas cerca de 10.000 bibliotecas escolares em todo Brasil. A partir de 1990, outros programas foram criados para incentivar a leitura de alunos, professores e da comunidade em geral, como o PROLER, o PRÓ-LEITURA, o Programa Nacional Biblioteca da Escola (PNBE), entre outros.

No Brasil, as políticas públicas de incentivo à leitura são, em sua maioria, vinculadas ao MEC e são efetivadas pelo Fundo Nacional de Desenvolvimento da Educação (FNDE). O FNDE é o órgão responsável pela execução da maioria das ações e programas da Educação Básica do Brasil, sendo o responsável pela operacionalização dos Programas do Livro².

No site do FNDE, encontramos menção a alguns programas, a algumas campanhas e a projetos de incentivo à leitura. De 1982 a 1985 foi desenvolvido o projeto Ciranda de Livros com o objetivo de distribuir e incentivar a leitura de literatura infantil e juvenil. O projeto distribuiu livros em trinta mil escolas da rede pública de ensino, de todo o país. O projeto Viagem da Leitura, desenvolvido entre 1987 e 1988, teve por objetivo oportunizar aos alunos do Ensino Fundamental das escolas públicas brasileiras o acesso ao livro de literatura infantil. Em 1988 é criado o projeto Sala de Leitura, esse projeto teve como foco abranger o sentido total de Biblioteca Escolar, incentivar e garantir a existência, na escola, de um espaço para a leitura.

Em 1997 foi criado a campanha "Quem lê viaja" que tinha como objetivo promover o livro e a leitura e foi destinado para todos os brasileiros. Em 2001 surge a campanha "Tempo de Leitura" o objetivo

2. Segundo o site do MEC, "[o] Programa Nacional do Livro e do Material Didático (PNLD) compreende um conjunto de ações voltadas para a distribuição de obras didáticas, pedagógicas e literárias, entre outros materiais de apoio à prática educativa, destinados aos alunos e professores das escolas públicas de educação básica do País". Disponível em: https://www.fnde.gov.br/programas/programas-do-livro. Acesso em: 14 jul. 2019. 
da campanha foi de incentivar os pais e responsáveis à prática da leitura compartilhada com as crianças e assim tornar o Brasil um país de leitores, o público-alvo foram os alunos de $4^{\mathrm{a}}, 5^{\mathrm{a}}$ e $8^{\mathrm{a}}$ séries. De 2001 a 2004 o programa Literatura em Minha Casa distribuiu uma coletânea de obras literárias para alunos de $4^{\mathrm{a}}$ e $5^{\mathrm{a}}$ séries do Ensino Fundamental. Em 2004 o programa Fome de Livro tinha com objetivo criar uma política pública para o livro, a leitura e a biblioteca pública no país. E a campanha "Viva a Leitura" ocorreu em 2005 e tinha como objetivo estimular e reconhecer as melhores experiências relacionadas à leitura e através de concurso premiá-las. Participaram dessa campanha escolas, professores, editores, bibliotecários, livreiros, organizações governamentais e não governamentais, meios de comunicação e empresas dos 21 países ibero-americanos.

As políticas públicas de incentivo à leitura se destinam principalmente para a distribuição de livros e não para efetivamente a formação de leitores, pois, como assegura Célia Regina Delácio Fernandes (2013), na obra Leitura, literatura infanto-juvenil e educação, entre livros e leitores há importantes mediadores que, além da família, têm no professor figura fundamental na construção de uma história de leitura para cada aluno. Afinal, "cabe a ele [mediador] o papel de desenvolver no aluno o gosto pela leitura a partir de uma aproximação afetiva e significativa com os livros" (FERNANDES, 2013, p. 32). O professor é a ponte entre alunos e alunas e os objetos culturais que deveriam estar ao alcance de todos. Sendo o livro literário um desses objetos, já que "ele promove a socialização, a informação, a formação de opinião e o desenvolvimento da capacidade criadora e inventiva sobre temáticas dos mais variados contextos" (OLIVEIRA, 2010, p. 51).

Portanto, ser mediador de leitura é conseguir compartilhar e apoiar o leitor para que ele possa explorar o mundo dos livros. E quando falamos sobre as questões étnico-raciais, o professor desempenha um papel crucial na (re)conquista da identidade negra, sendo capaz de estimular os leitores a compartilhar suas experiências e pontos de vista, permitindo que se apropriem da leitura para fazer transitar suas ideias e repensar os lugares da cultura popular negra dentro do ambiente escolar, tanto nos conteúdos das aulas quanto na relação dos alunos e alunas com a cultura, de modo que as pessoas racializadas também possam se ver representados e representar-se.

\section{Programa Nacional Biblioteca da Escola (PNBE)}

O PNBE foi criado no ano de 1997, durante o governo Fernando Henrique Cardoso. Esse programa, diferente de outras ações e campanhas de incentivo à leitura, avançou em termos de atendimento. As outras ações e campanhas de incentivo à leitura por diversas vezes estiveram ligadas ao governo da sua época, enquanto o PNBE se manteve e resistiu à troca partidária do Governo Federal: Fernando Henrique Cardoso ${ }^{3}$ (Partido da Social Democracia Brasileira - PSDB), Luís Inácio Lula da Silva ${ }^{4}$ (Partido dos Trabalhadores - PT), Dilma Rousseff ${ }^{5}$ (PT) e Michel Temer ${ }^{6}$ (Partido do Movimento Democrático Brasileiro - PMDB).

O PNBE é uma política pública e, segundo o Ministério da Educação (MEC), tem o objetivo de promover o acesso à cultura e o incentivo à leitura por meio da distribuição de acervos de obras de literatura, de pesquisa e de referência. O atendimento era feito de forma alternada: ou são contempladas as escolas de Educação Infantil, de Ensino Fundamental (anos iniciais) e de educação de jovens e adultos, ou são atendidas as escolas de Ensino Fundamental (anos finais) e de Ensino Médio.

De acordo com o site do $\mathrm{FNDE}^{7}$, o primeiro ano de atuação efetiva do PNBE foi 1998. O acervo distribuído foi composto por 215 títulos, incluindo obras clássicas e modernas da literatura brasileira,

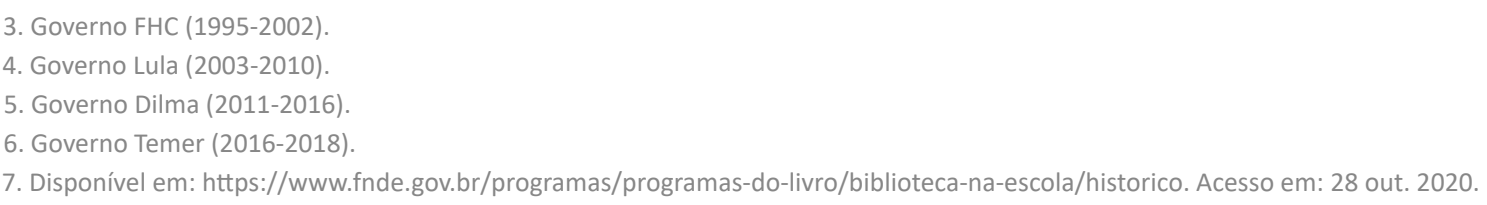


enciclopédias, atlas, globos terrestres, dicionários, livros de história do Brasil e sua formação econômica, e ainda um atlas histórico do Brasil 500 anos.

A iniciativa do PNBE, que estava descontinuada, extinguiu-se no mês de julho de 2017. O MEC incrementou uma medida ao Programa Nacional do Livro Didático (PNLD) para disponibilizar também obras literárias. O primeiro passo na elaboração de um substituto para o PNBE foi a edição do Decreto $n^{\circ}$ 9.099, de 18 de julho de 2017. A medida incorpora ao Programa Nacional do Livro Didático (PNLD) a obrigação de "avaliação e disponibilização de obras didáticas e literárias, além de acervos para bibliotecas [...], [incluindo] ações de qualificação de materiais para aquisição descentralizada pelos entes federativos” (BRASIL, 2017). A última remessa de livros do PNBE feita pelo Ministério da Educação (MEC) para toda a rede ocorreu em 2014. A partir daquele ano, o programa que garantia a compra e a entrega não foi mais executado.

\section{Literatura na escola}

Falamos, até aqui, sobre as políticas de incentivo à leitura no Brasil. Agora, é preciso falar sobre literatura na escola, porque as escolas são as principais promotoras e destinatárias das políticas de incentivo à leitura no Brasil.

Segundo a autora Magda Soares (2008), no texto “Ler, verbo transitivo", é obrigação da escola dar amplo e irrestrito acesso ao mundo da leitura, e isto inclui a leitura informativa, mas também a leitura literária. Ou seja, devemos oportunizar tanto a leitura para fins pragmáticos quanto a leitura de fruição ${ }^{8}$; a leitura que situações da vida real exigem, mas também a leitura que nos permita escapar por alguns momentos da vida real (SOARES, 2008, p. 33).

A leitura, percebida como direito, passa a ser garantida através da Constituição Federal de 1988 (BRASIL, 1988), que aponta no seu artigo 214, incisos I e II, a erradicação do analfabetismo e a universalização do atendimento escolar; em seu artigo 215, o comprometimento de que o Estado fornecerá formas de garantir a todos o total exercício dos direitos culturais e o acesso às fontes da cultura nacional, entre elas, a literatura.

A escola e a sala de aula devem funcionar como espaços promotores do diálogo entre texto e leitor, de modo que as leituras realizadas possam ser compartilhadas e estabelecidas como parte da realidade do aluno. Sendo assim e sabendo da importância da literatura na formação de futuros leitores, a discussão a respeito da leitura literária na escola se caracteriza como um importante instrumento para garantir o direito ao acesso ao livro e o direito à literatura, pois, como afirma Candido (2004, p. 193), "uma sociedade justa, pressupõe o respeito dos direitos humanos e a fruição da arte e da literatura em todas as possibilidades e em todos os níveis é um direito inalienável”.

\section{Caminhos seguidos}

Volto, agora, à pesquisa por mim desenvolvida, enquanto pesquisadora de Iniciação Científica ${ }^{9}$. O estudo foi organizado em dois momentos; primeiro realizei uma revisão bibliográfica sobre o conceito de raça no Brasil - utilizando Antonio Sergio Guimarães como principal referencial teórico - e sobre os

\footnotetext{
8. Leitura de fruição seria aquela que se faz pelo simples ler por prazer. Refere-se à leitura pela leitura ou do livro pelo livro. Sendo assim, essa leitura é uma forma de lazer, como a esportes, música ou pintura. É importante pensar a diferença entre aprender a ler e se tornar leitor, pois a concepção de leitura apoiada aqui vai muito além do que decodificar um código, mas sim entender que leitura é dar sentido ao que se leu para transformar o lido em um novo conhecimento.

9. Faço parte do projeto de pesquisa "O livro é um convite: projetos de leitura e formação de leitores na Educação Básica", o qual pretende refletir acerca da presença (ou ausência) da leitura literária e do letramento literário na Educação Básica, especificamente no Ensino Fundamental II. Então, precedentemente a pesquisa de minha autoria, foi preciso elaborar uma revisão bibliográfica sobre a leitura literária e o letramento literário na Educação Básica e ao estudo dos documentos que organizam o Colégio de Aplicação da UFRGS - local onde ambas as pesquisas são produzidas.
} 
conceitos de representação e representatividade - tendo como principal referência Stuart Hall -; no segundo momento, desenvolvi uma análise das obras literárias selecionadas pelo PNBE, para verificar quais representações de etnia estão presentes nesse acervo

A pesquisa adotou metodologia qualitativa e quantitativa. Para a análise quantitativa, sendo inviável a leitura de todo o acervo, foi realizada a leitura dos resumos dos livros nos sites das editoras, buscando a existência de personagens negros, tentando verificar, ainda, se os mesmos estavam em posição de destaque, como protagonistas. Considerei os dados contidos nos resumos das obras suficientes para dar seguimento ao recorte necessário para estudo. Nesse momento, foram selecionadas as obras a serem estudadas com aprofundamento e foram excluídas aquelas não possuíam representações de personagens-protagonistas negros.

\section{Escolha das obras}

Os critérios de avaliação das obras literárias do PNBE, juntamente com o programa, passaram por muitas transformações, aprimorando-se a cada edição. Nos primeiros anos do programa, os parâmetros não ficaram claros; somente a partir de 2001 eles foram estabelecidos em edital, publicado no Diário Oficial da União e colocado à disposição na internet.

O processo de seleção das obras literárias começa com a elaboração e a publicação do edital pelo MEC, que determina as regras a serem seguidas tanto por aqueles que vão concorrer (as editoras) como para aqueles que vão coordenar a avaliação pedagógica do PNBE (a universidade, a partir de 2005).

A partir do ano de 2006 até a extinção do programa, a seleção das obras de literatura ficou sob a responsabilidade do Centro de Alfabetização, Leitura e Escrita (Ceale), da Faculdade de Educação (FAE), da Universidade Federal de Minas Gerais (UFMG). Os critérios de seleção das obras são três: qualidade de texto, adequação temática e projeto gráfico.

Para Aparecida Paiva, coordenadora do processo de seleção de obras literárias do PNBE de 2006 a 2014, a tarefa de avaliar obras é bastante complexa, principalmente por causa do desafio maior de saber "se o que está sendo selecionado, como de qualidade, despertará o interesse do jovem leitor" (PAIVA, 2012, p. 302).

O edital de convocação para inscrição e seleção de obras de literatura para o PNBE, publicado no site do MEC, diz sobre os critérios de avaliação e seleção:

As obras de literatura a serem avaliadas e distribuídas pelo Programa Nacional Biblioteca da Escola 2013 deverão contribuir para que a escola pública brasileira possa levar os alunos a uma leitura emancipatória, por meio do acesso a textos literários de qualidade que proporcionem experiências significativas e ofereçam estímulos para a reflexão e a participação criativa na construção de sentidos para o texto. Além disso, os textos literários deverão ser portadores de manifestações artísticas capazes de despertar nos leitores jovens não apenas a contemplação estética, mas também, a capacidade de reflexão diante de si, do outro e do mundo que o cerca. O que se espera dessas obras é que elas ofereçam subsídios para a formação de leitores autônomos, apreciadores das várias possibilidades de leitura que um texto literário pode oferecer. (Brasil, 2011, p. 21).

Segundo o edital,

[s]erão selecionadas obras com temáticas diversificadas, de diferentes contextos sociais, culturais e históricos. Essas obras deverão estar adequadas à faixa etária e aos interesses dos alunos do ensino fundamental - anos finais e do ensino médio. (Brasil, 2011, p. 22).

Porém, o edital não apresenta especificações para definir quais obras são ou não adequadas para as faixas etárias a qual são destinadas. Toda seleção é excludente, sabemos, e, no mesmo edital, temos um trecho que especifica critérios eliminatórios: "Da mesma forma, não serão selecionadas obras que apresentem didatismos, que contenham teor doutrinário, panfletário ou religioso" (BRASIL, 2011, p. 22). 
Em outros termos, registra-se que o edital do PNBE fala em diversidade temática como critério, no entanto, não coloca como critério de seleção retratar, por exemplo, as diferenças étnicas e raciais, as diferenças de gênero, de idade ou de sexualidade.

$\mathrm{Na}$ análise qualitativa, as obras foram submetidas à verificação de conteúdo destacando a construção de personagem, tendo em vista características étnicas e raciais. Das 120 obras literárias disponibilizadas para o último ano do Ensino Fundamental, pelo PNBE do ano de 2013, apenas quatro apresentam protagonistas negros, como o gráfico abaixo demonstra:

\section{Gráfico 1 - Obras do acervo do PNBE 2013 ${ }^{10}$}

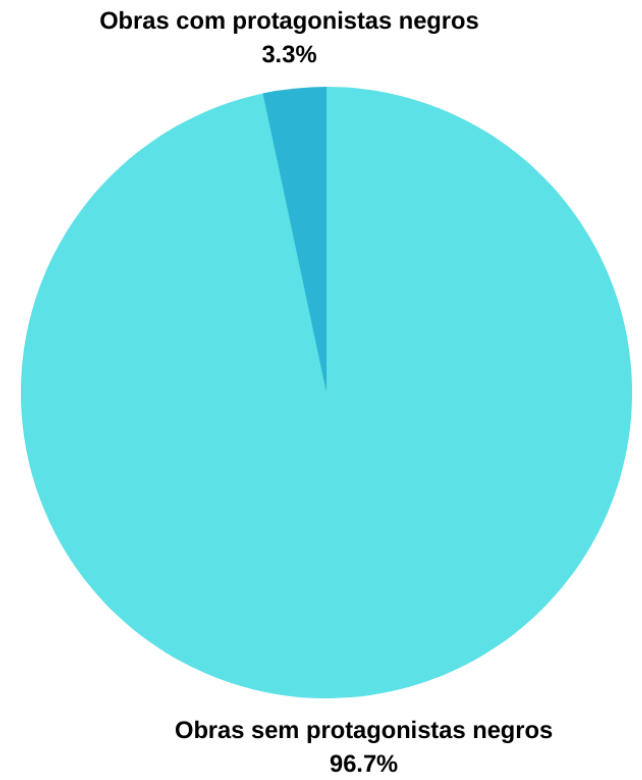

Fonte: Elaborado pela autora, com base no acervo do PNBE 2013.

Os critérios usados para análise das obras após selecioná-las no acervo do PNBE do ano de 2013 foram:

\section{Quadro 1 - Critérios usados para análise das obras do PNBE do ano de 2013}

\begin{tabular}{|l|l|}
\hline Critério 1 & $\begin{array}{l}\text { A presença e importância de personagens negras, se são narradoras/es, contando a própria história, } \\
\text { ou a história é narrada por outros. }\end{array}$ \\
\hline Critério 2 & $\begin{array}{l}\text { As ilustrações possuem valorização de aspectos fenotípicos ou com uso de símbolos relacionados } \\
\text { com africanidades, se as imagens valorizam os traços físicos das pessoas negras e também uma } \\
\text { valorização da cultura africana, reconhecendo, significando e ressignificando as práticas culturais } \\
\text { africanas. }\end{array}$ \\
\hline Critério 3 & $\begin{array}{l}\text { Temas relativos à história ou cultura africana ou africana da diáspora, se possui assuntos relacio- } \\
\text { nados e que valorizem à história e cultura africanas. }\end{array}$ \\
\hline Critério 4 & $\begin{array}{l}\text { Ausência de hierarquias entre personagens brancas e negras, se nas narrativas a cor da pele dos } \\
\text { personagens interfere na estrutura social dentro da obra. }\end{array}$ \\
\hline Critério 5 & $\begin{array}{l}\text { Presença ou não da/o branca/o como representante exclusivo de humanidade (branquidade } \\
\text { normativa), é ideia de que o normal é ser branco. }\end{array}$ \\
\hline
\end{tabular}
Fonte: Elaborado pela autora.

Importante ressaltar que as personagens analisadas são somente das obras literárias que apresentam protagonistas negras.

Antes de seguir para a análise quantitativa, foi preciso apropriar-me de alguns conceitos que nortearam a pesquisa, como raça, representação e representatividade. Assumo o conceito de "raça" como uma construção social, seguindo a perspectiva de Antonio Sergio Guimarães (1999), apresentada na obra Racismo e antirracismo no Brasil. A raça não se trata de um dado biológico, mas de "construtos sociais, formas de 
identidade baseadas numa ideia biológica errônea, mas eficaz socialmente, para construir, manter e reproduzir diferenças e privilégios"11 (GUIMARÃES, 1999, p. 147). Dessa forma, o conceito de raça traz consigo um reflexo de como a sociedade se organiza para criar distinções sociais e, consequentemente, desigualdade social, de acordo com os interesses das classes privilegiadas.

Outro conceito crucial para a análise dos livros é o de representação, o qual, segundo Stuart Hall (1997, p. 61), é "o processo pelo qual membros de uma cultura usam a linguagem para produzir sentidos", ou seja, representação seria a produção de sentido pela linguagem. Esse conceito de representação focaliza a linguagem, pois se refere à forma como o outro é apresentado, nomeado e dito nos diversos espaços e artefatos: televisão, histórias em quadrinhos, filmes, músicas, livros literários.

Sendo a escola a principal disseminadora da leitura no Brasil, é relevante que as obras literárias presentes no ambiente escolar consigam expressar a pluralidade de diferenças que existem entre as crianças e adolescentes. E também é crucial para a formação da identidade racial e da autoestima das pessoas negras se reconhecer naqueles que estão em evidência e lhes representam nas mais diversas áreas.

\section{Análise das obras}

Depois de observar o acervo disponibilizado pelo PNBE, em 2013, para os últimos anos do Ensino Fundamental, constatei que, entre as 120 obras selecionadas, quatro apresentam protagonistas negros. Nas demais obras, os personagens são majoritariamente brancos, o que não corresponde ao pertencimento étnico-racial da maioria das crianças do nosso país, pois, segundo os dados iniciais do Censo de 2019, ao agregarmos os pretos e pardos na categoria de negros, a população brasileira é composta por $55,8 \%$ de não brancos, o que corresponde a mais do que a metade da população brasileira.

As obras selecionadas para compor meu estudo foram estas: O negrinho do pastoreio, de André Diniz (2012); Você é livre!, de Dominique Torrès (2012); Kamazu, de Laura Caruso (2011) e Orixás: do Orum ao Ayê, de Alex Mir, Caio Majado e Omar Viñole (2011).

Na obra O negrinho do pastoreio, temos uma releitura da história do Negrinho do Pastoreio, cuja lenda é bastante conhecida na região sul do Brasil, trazendo uma mudança da postura submissa do personagem. Também estão na obra elementos da cultura afro presentes em antigas versões da lenda ${ }^{12}$, o que contribui para disseminar as diferentes influências dos povos africanos na cultura brasileira.

A personagem Negrinho, tanto na versão de André Diniz quanto nas versões mais antigas, tem Nossa Senhora Aparecida como madrinha, a qual é personificada tanto em sua forma cristã quanto no orixá feminino Oxum, mostrando, assim, as diversas religiões. O sincretismo religioso também se faz evidente na medida em que elementos da fé católica romana se mesclam a costumes e ingredientes culturais oriundos das culturas africanas. Na época da escravidão no Brasil, sendo as próprias autoridades do país católicas, ficava difícil ter outra religião que não o Catolicismo. As religiões afro-brasileiras como o candomblé, o xangô, o batuque, o tambor de Minas e a umbanda foram reprimidas e perseguidas pela polícia, pois temia-se que os negros através de seus rituais pudessem lançar maldições, fazer o mal (BISPO; BEVILACQUA; SANTOS, 2010). É relevante que uma obra literária apresente, de forma sutil, uma narrativa que demonstre a mistura das religiões no Brasil sem demonizar nenhuma.

\footnotetext{
11. Na triagem das obras que seriam analisadas, distingui - através dos resumos das mesmas - quando havia menção à cor da pele e/ou quando, nas ilustrações das capas, havia representação da cor da pele lida como negra.

12. A lenda "Negrinho do Pastoreio" conta a história de um fazendeiro que ordenou que um menino negro fosse pastorear os cavalos que ele havia comprado. No final do dia, com o retorno do menino, o fazendeiro notou que faltava um cavalo e deu uma surra de chicote no menino. O menino partiu em busca do cavalo perdido, encontrou-o, mas o animal fugiu novamente. De volta à fazenda, o fazendeiro estava mais irritado e bateu mais uma vez no menino e após amarrou-o em um formigueiro. No dia seguinte, quando ele foi ver o estado de sua vítima, tomou um susto. O menino estava lá, mas de pé, com a pele lisa, sem nenhuma marca dos castigos. Ao lado dele estava Nossa Senhora e o cavalo perdido. O fazendeiro se jogou no chão pedindo perdão, mas o Negrinho nada respondeu. Apenas beijou a mão da Santa, montou no cavalo e partiu. Desde então, quando qualquer cristão perdia alguma acendia uma vela ao Negrinho.
} 
O livro Você é livre! foi feito a partir de uma reportagem que investiga e denuncia a escravidão de pessoas no século XXI. Amsy, o protagonista, passa por um processo de entendimento e aceitação da condição de ser livre e traz, ao longo da história, uma reflexão sobre os direitos humanos. No começo da narrativa, a personagem não entende que existe a liberdade (isto é, uma vida não escravizada) e, com interferência de outro personagem, passa a compreender que a escravidão é crime. As ilustrações feitas com colagem de fotos evidenciam uma parte do continente africano, o Níger, com algumas de suas riquezas e especificidades. Isso contribui para conhecer e entender diversidade de culturas presentes nesse continente.

Ainda assim, os estereótipos que existem no mundo são formas práticas do preconceito. Segundo Antônio Olímpio de Sant'Ana (2005, p. 62), no texto "História e Conceitos Básicos sobre o Racismo e seus Derivados", "[c]om base em estereótipos, as pessoas julgam umas às outras". A desconstrução de estereótipos é fundamental no combate à redução das desigualdades sociais. Em Você é livre!, pode haver uma certa generalização, em um primeiro momento, ao mostrar uma parte do continente africano ainda tribal, sem cidades grandes, o que talvez consiga gerar um interessante debate e uma pertinente pesquisa em sala de aula, possibilitando desconstruir possíveis equívocos e generalizações, como presumir que todos os países do continente africano possuem a mesma cultura.

O livro Kamazu reconta uma versão da lenda angolana "O rapaz e o rio"13, trazendo elementos característicos da cultura angolana. Segundo a autora Carla Caruso, em seu blog pessoal,

Kamazu é um menino que tem uma condição de escravo em Angola, e ele, por meio de seu trabalho, inteligência e ligação com sonhos, torna-se livre e encontra seu lugar no mundo. É uma história tradicional, do ponto de vista do percurso de um herói, e também está vinculada à questão da escravidão na África. (CARUSO, 2013).

A personagem Kamazu, como a personagem Amsy, também passa pelo processo de entendimento e de aceitação da condição de ser livre; afinal, ele que antes era escravizado consegue alcançar a liberdade. As ilustrações feitas à base de uma técnica de pintura e colagem, as formas e as cores que compõem o livro são resultado de uma grande pesquisa realizada pela autora sobre a cultura angolana.

Figura 1 - Capa do livro Kamazu

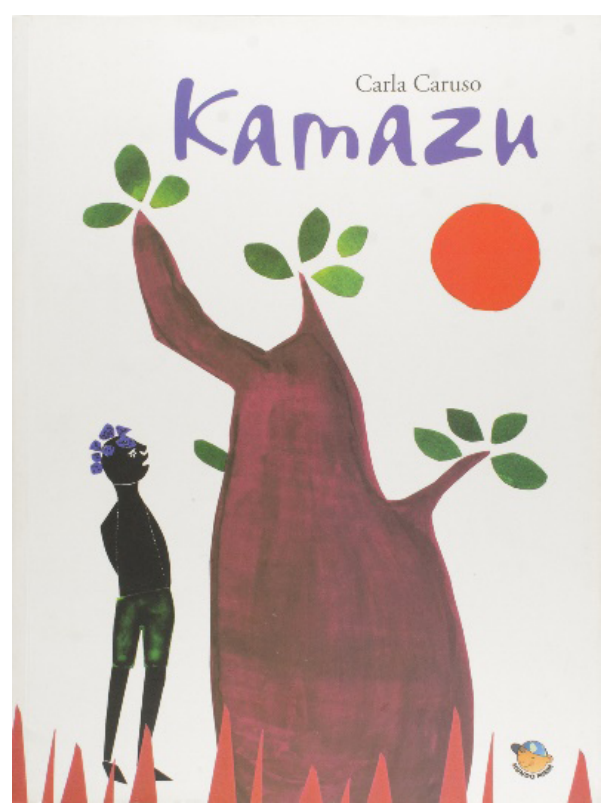

Fonte: Caruso (2011).

13. A lenda angolana conta a história de um menino escravizado que leva uma vida muito difícil até que, através de um sonho, recebe um presente do rio, uma caixa de ervas medicinais e uma pedra mágica. Com esses presentes, ele se torna um curandeiro muito rico e famoso, conseguindo comprar a sua liberdade. 
A história em quadrinhos Orixás: do Orum ao Ayê narra a história da criação do mundo a partir do ponto de vista dos orixás, segundo as lendas iorubás ${ }^{14}$. A obra é dividida em cinco capítulos e conta como Olorum criou os orixás, narra o surgimento da Terra, da humanidade e, por fim, a divisão entre o céu e a Terra. A obra contém notas de rodapé explicando alguns termos desconhecidos do público geral e justificando a escolha por determinadas grafias, quando existem diversas maneiras de escrever uma mesma palavra. A história exibe uma representação positiva do universo mitológico dos orixás e a valorização de histórias trazidas pelos negros escravizados que se espalharam por toda a América, o que contribui para desconstruir estereótipos e representar as religiões afro-brasileiras de modo positivo e valorizado. Segundo Debus e Vasques (2009, p. 142), "visualizar esses novos horizontes sobre o que representam as religiões afro-brasileira e africana significa quebrar paradigmas idealizadores que demonizam essas histórias mitológicas africanas".

Ao longo da narrativa, Olorum (deus supremo) decide criar um lugar para os orixás viverem. Assim, "em sua divindade, criou o ambiente perfeito para que os orixás vivessem em paz e harmonia" (MIR; MAJADO; VIÑOLE, 2011, p 17). Para demonstrar essa passagem, os autores investem na construção da ilustração: o ambiente é repleto de animais, plantas, riachos, montanhas e, nesse espaço, os orixás aparecem seminus.

Figura 2 - Lugar onde vivem os orixás

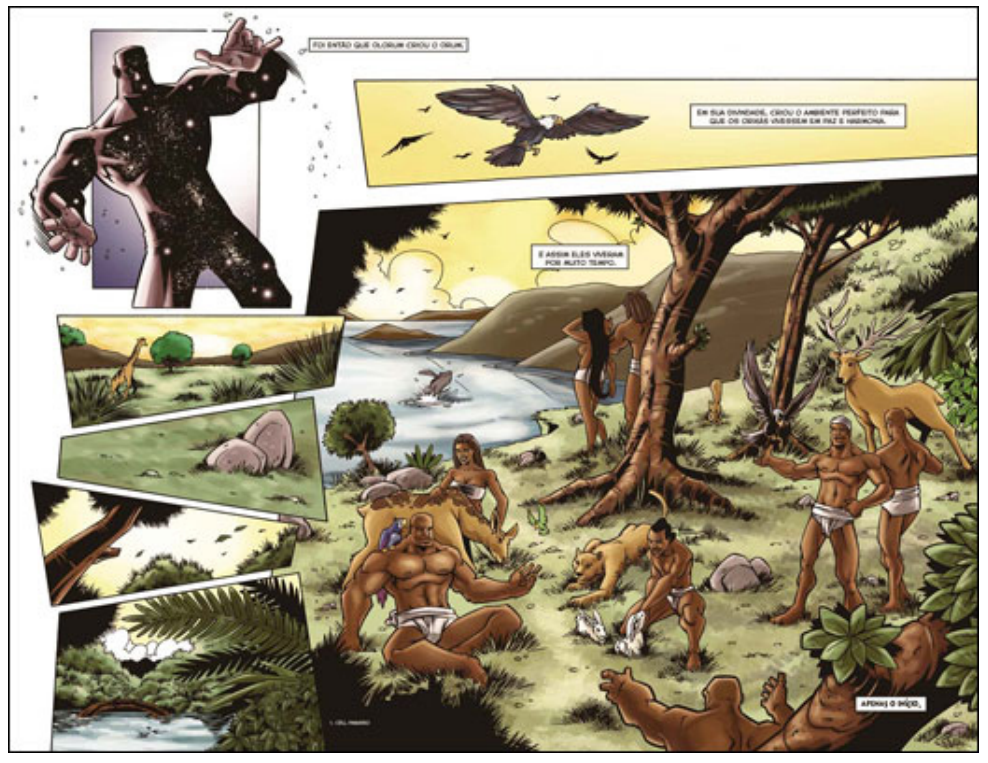

Fonte: Mir: Majado; Viñole (2011, pag. 8-9).

No segundo capítulo, Oxalá e Odudua aparecem em uma disputa de forças. Aqui, o que ganha destaque são os corpos dos orixás. A beleza do corpo é ressaltada, assim como os músculos e a força dos orixás masculinos. De acordo com Nobu Chinen (2013), no artigo "A religiosidade afro-brasileira nos quadrinhos”, há uma nítida influência da estética dos super-heróis na representação dos orixás ${ }^{15}$.

\section{Obras analisadas: personagens}

Em Kamazu e Orixás: do Orum ao Ayê, as personagens não têm descrições das suas características físicas, sendo descritas apenas pelas ilustrações.

\footnotetext{
14. Os iorubás, iorubas, iorubanos ou nagôs (em iorubá: Yorùbá) constituem um dos maiores grupos étnico-linguísticos da África Ocidental, com mais de 30 milhões de pessoas em toda a região. Trata-se do segundo maior grupo étnico na Nigéria, correspondendo a aproximadamente $21 \%$ da sua população total.

15. A obra Orixás: do Orum ao Ayê recebeu mais destaque nas análises pois, na minha percepção, é a obra que mais vai de encontro com a Lei 10.639/03 que alterou a Lei de Diretrizes e Bases da Educação que inclui no currículo oficial da rede de ensino a obrigatoriedade da presença da temática "História e Cultura Afro-Brasileira e Africana".
} 


\section{Figura 3 - Personagem Kamazu}
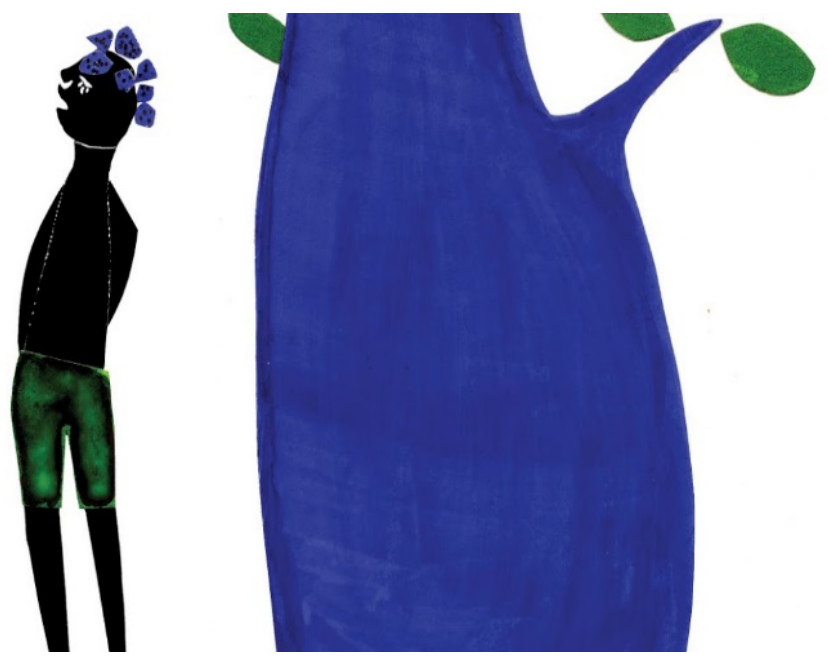

Fonte: Caruso (2011, p. 1).

\section{Figura 4 - Disputa entre os personagens}

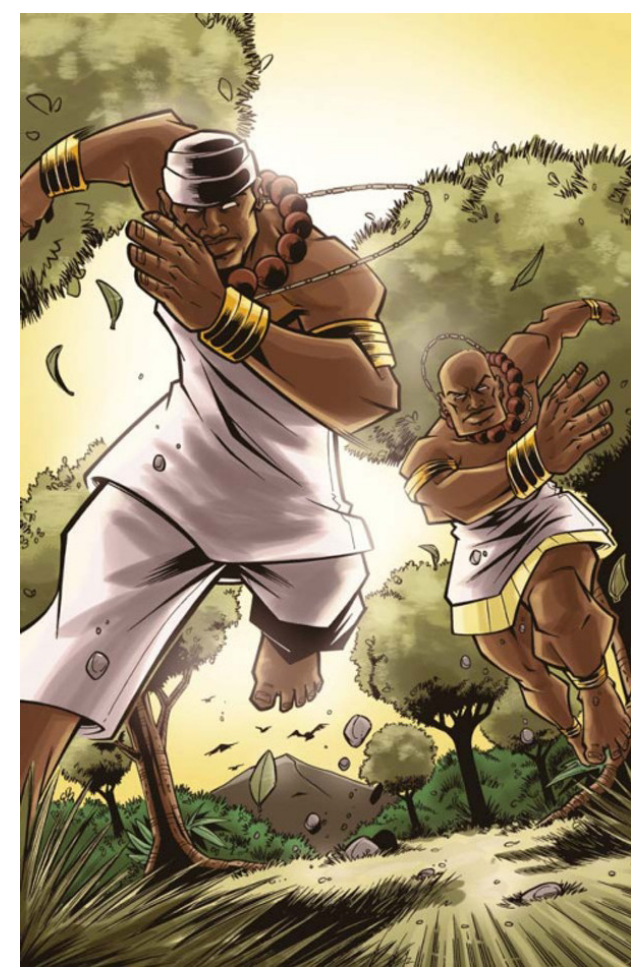

Fonte: Mir; Majado; Viñole (2011, p. 19).

Em Você é livre!, temos o personagem protagonista apresentado em ilustração apenas na capa, e a descrição de etnia vem em comparação com outros personagens, como nos trechos: "Quando está de bom humor, ele até os chama de os dois senhores do deserto: o branco e o negro!” (TORRÈS, 2012, p. 14). Nesse trecho, o personagem Amsy se refere ao homem que o escraviza, o qual afirma que a diferença entre as duas crianças é a cor da pele, sendo o menino branco filho desse homem. E nesse outro trecho, "[o] desconhecido deve ter uns trinta anos. Tem a pele negra como a do menino, mas suas roupas são boas, limpas, e usa um belo turbante branco, imaculado, amarrado à maneira dos tuaregues.” (TORRĖS, 2012, p. 16), o narrador relata o primeiro encontro em Amsy e o homem que irá lhe ensinar que ele tem direito de ser livre. 
Figura 5 - Capa do livro Você é livre!

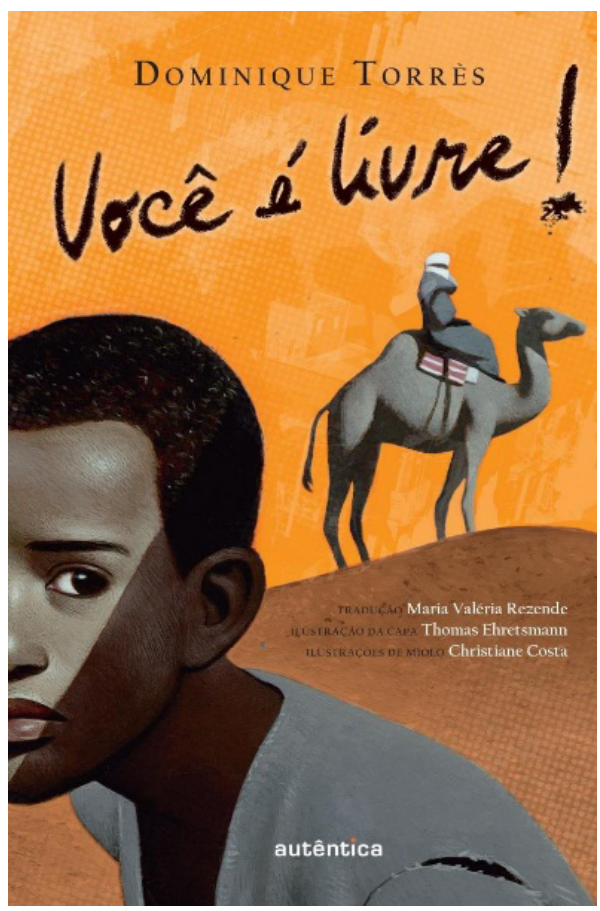

Fonte: Torrès (2012).

Em O Negrinho do Pastoreio, a personagem é descrita como escravizada e tem a cor da sua pele evidenciada em diversos momentos da narrativa. Na imagem abaixo, podemos observar que o protagonista se vê em comparação à Nossa Senhora Aparecida:

Figura 6 - Personagem Negrinho

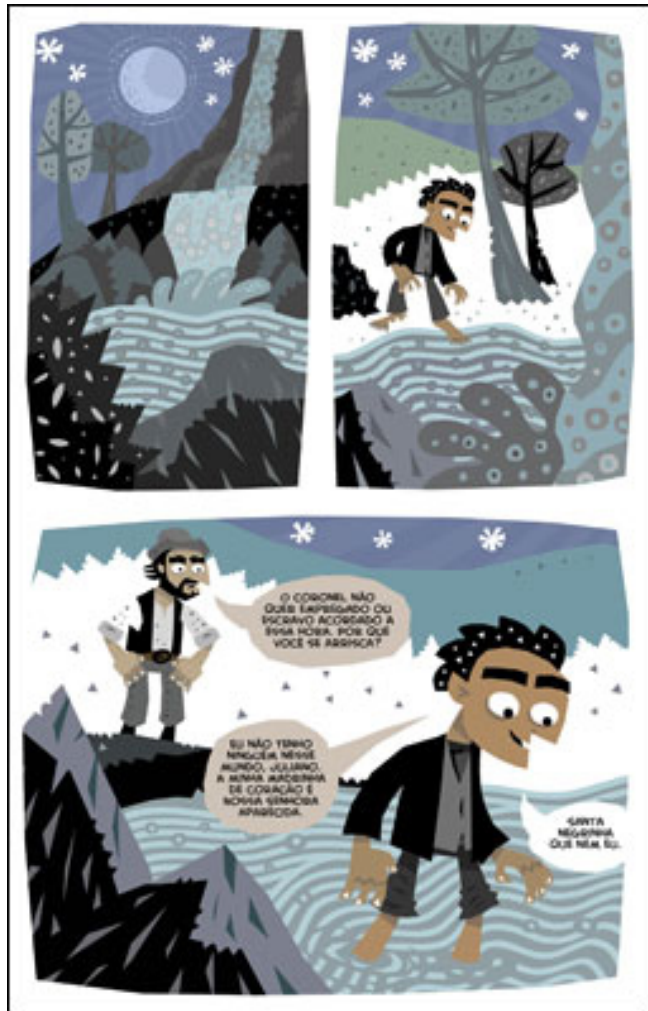

Fonte: Diniz (2013) 


\section{Considerações finais}

Observei que as quatro obras (O Negrinho do Pastoreio, de André Diniz; Você é livre!, de Dominique Torrès; Kamazu, de Laura Caruso e Orixás: do Orum ao Ayê, de Alex Mir, Caio Majado e Omar Viñole), de modo geral, valorizam aspectos culturais, enaltecem e reconhecem a cultura e a história africana, a identidade do povo negro. Alinhando-se às ponderações de Tomaz Tadeu Silva (1999, p. 64), segundo a qual "a produção da identidade e da diferença se dá, em grande parte, na e por meio da representação", as representações encontradas nas obras analisadas contribuem para negros "orgulharem-se de sua origem africana; para os brancos, permitir que identifiquem as influências, as contribuições, a participação e a importância da história e da cultura dos negros, no seu jeito de ser, viver, de se relacionarem com as outras pessoas" (Brasil, 2004, p. 7).

É inegável que as obras de literatura juvenil do acervo do PNBE, ao destacar aspectos do continente africano, suas tradições, contos, religiosidade, possibilita não só novas leituras daquelas culturas, mas também a construção de novas identidades e novos conhecimentos, contribuindo sobremaneira para uma educação antirracista.

A literatura infanto-juvenil, com suas características estéticas que se configuram principalmente pela relação entre texto, ilustração e projeto gráfico, cria os mais variados significados, provoca emoções, leva ao devaneio, apresenta conceitos, lança questões filosóficas, culturais e sociais. Dessa maneira, sua importância na formação de leitores sensíveis e críticos é fundamental.

Ainda que algumas perguntas tenham sido respondidas, outras permanecem abertas. Dentre elas, como é possível ainda existir uma produção que mantém uma porcentagem alta de livros na qual não há a presença de personagens negros, quando a população brasileira tem mais de $50 \%$ de negros?

\section{Referências}

BISPO, Alexandre Araujo; BEVILACQUA, Juliana Ribeiro da Silva; SANTOS, Renata Aparecida Felinto dos (coord.). Cultura afro: livro do aluno. São Paulo: DCL, 2010. (Coleção Civilização Brasileira).

BRASIL. [Constituição (1988)]. Constituição da República Federativa do Brasil. Brasília, DF: Presidência da República [2020].

BRASIL. Ministério da Educação. Edital de Convocação 08/2011: CGPLI. Edital de Convocação para Inscrição e Seleção de Obras de Literatura para o Programa Nacional Biblioteca da Escola - PNBE 2013. Brasília, DF: MEC, 2011. Disponível em: https://www.fnde.gov.br/programas/programas-do-livro/consultas/editais-programas-livro/item/ 3980-edital-pnbe-2013. Acesso em: 28 out. 2020.

BRASIL. Ministério da Educação. Programa Nacional Biblioteca da Escola (PNBE): leitura e bibliotecas nas escolas públicas brasileiras. Brasília, DF: MEC, 2008.

BRASIL. Ministério da Educação. Parecer CNE/CP nº 003/2004. Diretrizes Curriculares Nacionais para a Educação das Relações Étnico-Raciais e para o Ensino de História e Cultura Afro-Brasileira e Africana. Diário Oficial da União: seção 1, Brasília, DF, p. 19, 19 maio 2004. Disponível em: http://portal.mec.gov.br/dmdocuments/cnecp_003.pdf. Acesso em: 18 set. 2019.

CANDIDO, Antônio. O direito à literatura. In: CANDIDO, Antônio. Vários escritos. 4. ed. Rio de Janeiro: Ouro sobre Azul; São Paulo: Duas Cidades, 2004.

CARUSO, Carla. Artigo sobre a tímida presença de personagens negros na Literatura infantojuvenil brasileira, publicado pela Carta Escola. Carla Caruso, São Paulo, 19 ago. 2013. Disponível em: https://carlacarusolivros.blogspot. com/2013/08/texto-sobre-o-negro-na-literatura.html. Acesso em: 15 maio 2020.

CARUSO, Carla. Kamazu. São Paulo: Editora Mundo Mirim, 2011.

CHINEN, Nobu. A religiosidade afro-brasileira nos quadrinhos. Identidade!, São Leopoldo, v. 18, n. 1, p. 39-54, jan./jun. 2003.

DINIZ, André. O Negrinho do Pastoreio. Rio de Janeiro: Ygarapé, 2013.

DEBUS; Eliane Santana Dias; VASQUES, Margarida Cristina. A linguagem literária e a pluralidade cultural: contribuições para uma reflexão étnico-racial na escola. Conjectura, Caxias do Sul, v. 14, n. 2, p. 133-144, maio/ago. 2009. 
FERNANDES, Célia Regina Delácio. Leitura, literatura infanto-juvenil e educação. Londrina: Eduel, 2013. Disponível em: http://www.uel.br/editora/portal/pages/arquivos/LEITURA\%20INFANTO\%20JUVENIL_DIGITAL.pdf. Acesso em: 18 fev. 2019.

GUIMARÃES, Antonio Sergio. Racismo e antirracismo no Brasil. Rio de Janeiro: Editora 34, 1999.

HALL, Stuart. A centralidade da cultura: notas sobre as revoluções de nosso tempo. Educação \& Realidade, Porto Alegre, v. 22, n. 2, p. 15-46, 1997.

MIR, Alex; MAJADO, Caio; VIÑOLE, Omar. Orixás: do Orum ao Ayê. São Paulo: Marco Zero, 2011.

OLIVEIRA, Ana Arlinda de. O professor como mediador das leituras literárias. In: PAIVA, Aparecida; MACIEL, Francisca; COSSON, Rildo (coord.). Literatura: ensino fundamental. Brasília, DF: MEC/SEB, 2010. (Coleção Explorando o Ensino, v. 20).

PAIVA, Aparecida. Selecionar é preciso, avaliar é fundamental: acervos de literatura para jovens leitores. Educação, Porto Alegre, v. 35, n. 3, p. 301-307, set./dez. 2012.

SANT'ANA, Antônio Olímpio de. História e Conceitos Básicos sobre o Racismo e seus Derivados. In: MUNANGA, Kabengele (org.). Superando o racismo na escola. 2. ed. Brasília, DF: MEC/SECADI, 2005. p. 38-67.

SILVA, Tomaz Tadeu. Documentos de identidades. Belo Horizonte: Autêntica, 1999.

SOARES, Magda. Ler, verbo transitivo. In: PAIVA, Aparecida et al. (org.). Leituras Literárias: discursos transitivos. Belo Horizonte: CEALE: Autêntica, 2008.

TORRÈS, Dominique. Você é livre. Belo Horizonte: Autêntica, 2012.

YUNES, Eliana. Por uma política nacional de leitura. In: BRASIL. Ministério da Educação e do Desporto. A formação do Leitor: o papel das instituições de formação do professor para a educação fundamental. Brasília, DF: MEC, 1994.

Data de submissão: 29/07/2020

Data de aceite: 31/08/2020 